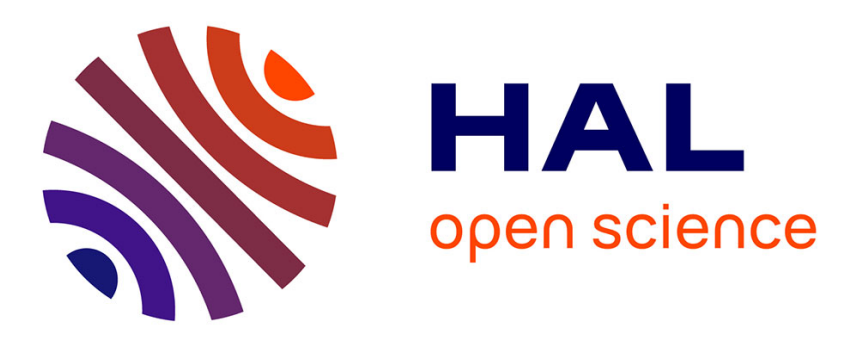

\title{
Adaptive response of yeast cells to triggered toxicity of phosphoribulokinase
}

\author{
Catherine Rouzeau, Adilya Dagkesamanskaya, Krzysztof Langer, Jérôme
} Bibette, Jean Baudry, Denis Pompon, Véronique Le Berre

\section{To cite this version:}

Catherine Rouzeau, Adilya Dagkesamanskaya, Krzysztof Langer, Jérôme Bibette, Jean Baudry, et al.. Adaptive response of yeast cells to triggered toxicity of phosphoribulokinase. Research in Microbiology, 2018, 169 (6), pp.335 - 342. 10.1016/j.resmic.2018.06.002 . hal-01849556

\section{HAL Id: hal-01849556 https://hal.science/hal-01849556}

Submitted on 4 Jun 2019

HAL is a multi-disciplinary open access archive for the deposit and dissemination of scientific research documents, whether they are published or not. The documents may come from teaching and research institutions in France or abroad, or from public or private research centers.
L'archive ouverte pluridisciplinaire HAL, est destinée au dépôt et à la diffusion de documents scientifiques de niveau recherche, publiés ou non, émanant des établissements d'enseignement et de recherche français ou étrangers, des laboratoires publics ou privés. 
Catherine Rouzeau ${ }^{\mathrm{a}}$, Adilya Dagkesamanskaya ${ }^{\mathrm{a}}$, Krzysztof Langer ${ }^{\mathrm{b}}$, Jérôme Bibette ${ }^{\mathrm{b}}$, Jean Baudry ${ }^{\mathrm{b}}$, Denis Pompon ${ }^{\mathrm{a}}$ and Véronique Anton-Leberre ${ }^{\mathrm{a} *}$

aLISBP, Université de Toulouse, CNRS, INRA, INSA, Toulouse, France

bLaboratoire Colloïdes et Matériaux Divisés, from the Institute of Chemistry, Biology and Innovation (CBI) - ESPCI ParisTech, CNRS - UMR 8231, PSL* Research University, 10 rue Vauquelin, 75005 Paris, France

Correspondance to: V. Anton-Leberre, LISBP - INSA Toulouse - 135 avenue de Rangueil - 31077 Toulouse CEDEX 04, France - Email: veronique.leberre@insa-toulouse.fr.

\section{Abstract}

Adjustment of plasmid copy number resulting from the balance between positive and negative impacts of borne synthetic genes, plays a critical role in the global efficiency of multistep metabolic engineering. Differential expression of co-expressed engineered genes is frequently observed depending on growth phases, metabolic status and triggered adjustments of plasmid copy numbers, constituting a dynamic process contributing to minimize global engineering burden. A yeast model involving plasmid based expression of phosphoribulokinase (PRKp), a key enzyme for the reconstruction of synthetic Calvin cycle, was designed to gain further insights into such a mechanism. A conditional PRK expression cassette was cloned either onto a low (ARS-CEN based) or a high (2-micron origin based) copy number plasmid using complementation of a trp1 genomic mutation as constant positive selection. Evolution of plasmid copy numbers, PRKp expressions, and cell growth rates were dynamically monitored following gene de-repression through external doxycycline concentration shifts. In the absence of RubisCO encoding gene permitting metabolic recycling, PRKp expression that led to depletion of ribulose phosphate, a critical metabolite for aromatic amino-acids biosynthesis, and accumulation of the dead-end diphosphate product contribute to toxicity. Triggered copy number adjustment was found to be a dynamic process depending both on plasmid types and levels of PRK induction. With the ARS-CEN plasmid, cell growth was abruptly affected only when level PRKp expression exceeded a threshold value. In contrast, a proportional relationship was observed with the 2-micron plasmid consistent with large copy number adjustments. Micro-compartment partitioning of bulk cultures by embedding individual cells into inverse culture medium/oil droplets, revealed the presence of slow and fast growing subpopulations that differ in relative proportions for low and high copy number plasmids.

Keywords: plasmid burden, cell toxicity response, population heterogeneity, metabolic engineering 


\section{Introduction}

Yeast and E. coli are major industry relevant microorganisms used for bulk chemicals or specialized productions (Borodina and Nielsen, 2014) (Chen et al., 2013) (Khatun et al.,2017) (Kwak and Jin, 2017) (Kim et al., 2017) (Wells and Robinson, 2017). ARS-CEN and $2 \mu$-replicon based S. cerevisiae plasmids are commonly used for metabolic engineering (Krivoruchko et al., 2011) (Gnügge and Rudolf, 2017) (Da Silva and Srikrishnan, 2012). In the case of ARS-CEN plasmids, replication and partitioning between daughter cells are synchronous with chromosomal DNA and copy number is maintained at about a single copy per cell (Clarke and Carbon, 1980). In contrast, $2 \mu$-replicon based plasmids are present with a highly variable copy number (10-40 copies per haploid genome) depending on engineering types and growth conditions (Gerbaud and Guérineau, 1980) (Futcher and Cox, 1984) (Kazemi Seresht et al., 2013) (Gnügge et al., 2016). Plasmid replication has a fitness cost in addition to specific positive or negative effects associated with included expression cassettes (Da Silva and Srikrishnan, 2012) (Futcher and Cox, 1983) (Görgens et al., 2001). The burden associated with copy number was evaluated to affect growth of the yeast cell by $\sim 0.2 \%$ per copy for $2 \mu$-based plasmid (Harrison et al., 2012), independently of expression cassettes. Similar data has been obtained for multicopy plasmid in E. coli (Bailey, 1993). In response, cells with high-copy number plasmids are counter-selected resulting into copy number adjustment. Promoter strengths of expressed gene, strain ploidy and selection marker nature can similarly affect cell growth (Kazemi Seresht et al., 2013) (Görgens et al., 2001) (Karim et al., 2013) (Çakar et al., 1999) (Ugolini et al., 2002). For example, auxotrophy complementation markers have been classified in decreasing order, HIS TRP > URA > LEU, based on their associated plasmid burden (Karim et al., 2013).

Copy number of episomal DNA affects expression of embedded gene(s). This generally results in an advantage with multi-copy plasmids when high level expression of a single heterologous protein is needed. Depending on the host micro-organism considered, expression cassettes involved in multistep engineering can be scattered between genomic and episomal elements. In the case of $S$. cerevisiae, availability of a large range of low and high copy number vectors makes multiple plasmid engineering generally easier and more versatile to implement. Modulation of gene expressions resulting from relative copy number changes in addition to the use of variable promoter strength plays a critical role in tuning multi-step metabolic coupling. Copy number of plasmids, like the $2 \mu$-based yeast replicon, has a tendency to naturally adjust in response to the balance between positive/negative selections, generally to limit accumulation of potentially toxic metabolite intermediates (Karim et al., 2013).

However, and while they are regulated by complex mechanisms, multi-copy plasmid replication and their distribution in daughter cells remains in part stochastic (Yen-Ting-Liu et al., 2014). This results into variable balances between coupled activities from cell to cell. Such effects might significantly alter productivity depending on the possibility of diffusion of accumulated metabolic intermediates between cells. In contrast, heterogeneity of gene expression between cells can be an advantage to survive external stress and contribute to robustness (Holland et al., 2014) (Guyot et al., 2015). Latest technological advancements give the possibility to study in more details plasmid encoded gene expression in individual cells. Stochastic fluctuation of gene transcription and translation at the single cell level are additional contributors to phenotypic diversity of clonal cells (Avery, 2006) can be evidenced by flow cytometry or time-lapse microscopy of fluorescently labelled cells (Bódi et al., 2017) (Talia et al., 2007), milli- or micro-fluidic technologies allow monitoring individual cell growth-rate in large populations (Grünberger et al., 2014) (Damodaran et al., 2015) (Grünberger et al., 2017) (Boitard et al., 2012), while quantification of DNA molecules by droplet digital PCR (ddPCR) combined with cell sorting using flow cytometry allows highly precise determination of plasmid copy number (Jahn et al., 2015) (Jahn et al., 2014). 
Carbon dioxide capture involving reconstruction of Calvin cycle was reported both in E.coli and $S$. cerevisiae (Watson et al., 2016, Guadalupe-Medina et al., 2013). A critical step of this engineering is the conversion by the PRKp of the natively present ribulose-5-phosphate into the corresponding 1, 5diphosphate, the substrate of the RuBisCO carbon dioxide fixing enzyme. When expressed alone, PRKp activity is highly toxic, both for E.coli and $S$. cerevisiae, due to the resulting depletion of the ribulose 5-phosphate pool, which is critical for aromatic amino-acid and nucleotide biosynthesis, and to the accumulation of dead-end diphosphate product. Successful reconstruction of a Calvin cycle thus critically depends on the balanced expression level of the PRKp in the absence of the multicomponent biochemical regulations that controls PRKp activity in natural photosynthetic organisms (Zhuang and Li, 2013). A synthetic model was built in yeast to evaluate how adjustments to average plasmid copy number occur following conditional promotor controlled changes in PRKp expressing cells.

\section{Materials and methods}

\subsection{Yeast strains and plasmids}

Plasmids pPRK-CEN (ARS416-CEN4, HA tagged S. elongatus PRK gene under the transcriptional control of the TETO7 promoter and TRP1 selection marker) and PPRK-2 $\mu$ (2 $\mu$-origin of replication associated to the same functional cassettes) were used to transform Saccharomyces cerevisiae CENPK1605 strain (MATa leu2-3,112 trp1-289 ura3-52). Resulted strains were named 1605-PRK-CEN and $1605-\mathrm{PRK}-2 \mu$ respectively.

\subsection{Media, growth conditions and sampling.}

The strains were grown at $30^{\circ} \mathrm{C}$ in YNB-trp liquid or solid (20 g/l of Agar) medium, containing $0.67 \%$ (w/v) Yeast Nitrogen Base with ammonium sulfate (Euromedex) and $2 \%(w / v)$ glucose and completed with drop-out synthetic mix without tryptophan (USBiological).

The frozen cells were spread on a plate containing solid YNB-trp with $2 \mu \mathrm{g} / \mathrm{ml}$ of doxycycline (Dox, Sigma-Aldrich). After 48 hours incubation at $30^{\circ} \mathrm{C}$, cells were collected and washed three times with YNB-trp without Dox and resuspended in the different liquid media supplemented with three different concentrations of Dox: $0,0.2$ or $2 \mu \mathrm{g} / \mathrm{ml}$ at $\mathrm{OD}_{600} 0.01$. Cell growth over time was monitored based on $\mathrm{OD}_{600 \mathrm{~nm}}$. The cell concentration was deduced using the equivalence between $1 \mathrm{OD}_{600}=10^{7} \mathrm{cells} / \mathrm{ml}$. Every two hours, a volume of culture was sampled for qPCR and PRKp activity measurements. The samples were centrifuged $\left(5 \mathrm{~min}, 13000 \mathrm{rpm}, 4^{\circ} \mathrm{C}\right)$, supernatant removed and cells stored at $-80^{\circ} \mathrm{C}$.

\subsection{Yeast cell lysis and total DNA extraction.}

Frozen yeast cells were resuspended in lysis buffer (10 mM Na-phosphate [pH 7.5], $1.2 \mathrm{M}$ sorbitol, 2.5 $\mathrm{mg} / \mathrm{ml}$ Zymolyase 20T Euromedex UZ1000) and incubated for $10 \mathrm{~min}$ at $37^{\circ} \mathrm{C}$ to digest the cell wall. Cell suspension was temperature cycled at $94^{\circ} \mathrm{C}$ for $15 \mathrm{~min},-80^{\circ} \mathrm{C}$ for $5 \mathrm{~min}$, and $94^{\circ} \mathrm{C}$ for $15 \mathrm{~min}$ (Moriya et al., 2006). Centrifuged supernatant containing DNA was stored at $-20^{\circ} \mathrm{C}$ before Q-PCRs analysis.

\subsection{Real-time Q-PCR.}

The plasmid copy number was estimated by comparing the relative quantity of plasmid encoded PRK gene to single copy chromosomal ALG9 gene. The estimated plasmid copy number was calculated by $2^{\Delta C \text { t(ALG9-PRK) }}$ (Moriya et al., 2006). The DNA levels were analyzed using the MylQ real-time PCR system from Bio-Rad with the software Bio-Rad iQ5 2.0. The Ct were determined by the software. Each sample was tested in duplicate in a 96-well plate (Bio-Rad, CA). The reaction mix (20 $\mu$ final volume) was composed of $10 \mu \mathrm{l}$ of Sso Advanced Universal SYBR Green Supermix (Bio-Rad), $0.4 \mu \mathrm{l}$ of each primer 
(Table S1. Alg9 sequences used for a described in (Teste et al., 2009)) at $0.2 \mu \mathrm{M}$ final concentration, $5.2 \mu \mathrm{l}$ water, and $4 \mu \mathrm{l}$ of a 1:10 dilution of the DNA samples. A blank (no template) and a positive control were also included in each assay. The thermocycling program consisted of one hold at $95^{\circ} \mathrm{C}$ for $30 \mathrm{~s}$ followed by 40 cycles of $10 \mathrm{~s}$ at $95^{\circ} \mathrm{C}$ and $45 \mathrm{~s}$ at $54^{\circ} \mathrm{C}$. After the amplification, a melting curve analysis with a temperature gradient of $0.1^{\circ} \mathrm{C} / \mathrm{s}$ from 70 to $95^{\circ} \mathrm{C}$ was performed to verify PCR specificity, contamination and the absence of primer dimers.

\subsection{HPLC-MS determination of PRK activity.}

Cell pellets were resuspended in two volumes of cold lysis buffer $(100 \mathrm{mM} \mathrm{Tris/HCl} \mathrm{buffer} \mathrm{[pH7.9],} 10$ $\mathrm{mM} \mathrm{MgCl} 2,100 \mathrm{mM} \mathrm{NaCl}$ ), the suspension was put in a FastPrep tube filled with one volume of $500 \mu \mathrm{m}$ glass beads (Sigma-Aldrich). The cells were broken using a FastPrep FP120 (MPBiomedicals) with a setting of $6.0 \mathrm{~m} / \mathrm{s}$ and 6 cycles of $20 \mathrm{~s}$ 'on' / 20sec 'off' in ice. The tubes were centrifuged (13 $000 \mathrm{rpm}$, $4^{\circ} \mathrm{C}, 5 \mathrm{~min}$ ) and the supernatant (containing the cell extract) was recovered and stored at $-80^{\circ} \mathrm{C}$. Prior to use, the protein extract was centrifuged again $\left(13000 \mathrm{rpm}, 4^{\circ} \mathrm{C}\right)$ in order to eliminate aggregates. Total protein content was determined by using the Bradford assay (Sigma Aldrich).

The PRKp activity was quantified by monitoring conversion of ribulose-5-phosphate to the 1,5diphosphate derivative. Protein extracts $(12.5 \mu \mathrm{l})$ in a 96 -well plate were mixed on ice with $12.5 \mu \mathrm{l}$ of $4 \mathrm{X}$ assay buffer ( $400 \mathrm{mM}$ Tris [pH7.9], $40 \mathrm{mM} \mathrm{MgCl}, 400 \mathrm{mM} \mathrm{NaCl}, 8 \mathrm{mM}$ ATP). Reaction was initiated by $25 \mu \mathrm{l}$ of $2 \mathrm{mM}$ ribulose-5-phosphate (Sigma-Aldrich) in water. The microplate was incubated for $30 \mathrm{~min}$ at $30^{\circ} \mathrm{C}$ and the enzymatic reaction was stopped by heating for $7 \mathrm{~min}$ at $90^{\circ} \mathrm{C}$. The plate was centrifuged and supernatants diluted two times with water and stored at $-80^{\circ} \mathrm{C}$ before analysis.

HPLC analysis was performed on Waters separation module 2790 coupled to Waters micromass ZQ2000. Separation was achieved on a Sheri-5 RP185 column (100-2.1 mm) (PerkinElmer) with mobile phase consisting of tributylamine acetate (TBA) pH5.7 and acetonitrile (ACN). Elution was performed at $1 \mathrm{ml} / \mathrm{min}$ with $100 \%$ TBA for $1 \mathrm{~min}$, a 100:0 to 70:30 TBA:ACN linear gradient for $15 \mathrm{~min}$, and a 70:30 to 0:100 TBA:CAN linear gradient for $18 \mathrm{~min}$. lons at $\mathrm{m} / \mathrm{e}=229.0$ (ribulose-5-phosphate), 309.0 (ribulose-1.5-biphosphate), 426.3 (ADP) and 506.3 (ATP) were monitored. PRK activity was expressed in $\mu$ moles of ribulose-1,5-biphosphate formed per min and $\mathrm{mg}$ of total proteins.

The enzymatic activity measurement was carried out starting from 13 hours of incubation as cell quantities in earlier time points were too low to obtain a detectable activity.

\subsection{Observations in reverse emulsion.}

Microfluidic devices (droplets generation chip and observation chambers (Fig. S1) were provided by the Laboratory Colloïdes et Matériaux Divisés (LCMD) from Ecole Supérieure de Physique et Chimie Industrielles of Paris (ESPCI). To generate the emulsion, cultures were diluted to $\mathrm{OD}_{600}=0.015$ in order to encapsulate mostly a single cell per droplet. In such conditions of limit dilution, a large majority of droplets remained empty (Fig.S1D). The emulsion was made by flow-focusing the cell suspension stream with two streams of HFE7500 fluorinated oil (3M) containing $2 \%(\mathrm{w} / \mathrm{w})$ 008-FluoroSurfactant (RAN Biotechnologies) (Boitard et al., 2012). The droplets were incubated at $30^{\circ} \mathrm{C}$ in a $1.5 \mathrm{ml}$ tube. After 24 hours of incubation at $30^{\circ} \mathrm{C}$, a monolayer of droplets was observed in a custom-made glass chamber with 40-um depth using a direct microscope LEICA DM4000B. Snapshots were taken with LEICA DFC300FX camera. Three classes of growth were differentiated: droplets with no or weak growth ( 1 or 2 cells/droplet), droplets with few cell divisions (3 to 10 cells/droplet) and droplets with many cell divisions (more than 10 cells/ droplet). About a hundred droplets exhibiting each cell growth phenotype were counted. 


\section{Results and discussions}

\subsection{Experimental cell model}

S. cerevisiae cells were transformed with a low copy number pPRK-Cen or a high copy number 2micron origin based pPRK-2 $\mu$ plasmid bearing a synthetic cassette encoding a PRK synthetic gene under the transcriptional control of a Dox repressed (tet-off) promoter (Dingermann et al., 1992). ARSCEN plasmids synchronously replicate with chromosomal material and are generally present in yeast at a single copy (in average between 1 and 2 due replication during cell division). In contrast, copy number of $2 \mu$-plasmids can be highly variable, ranging from single copy when counter-selected, to values than can exceed 80 when they are strongly positively selected. ARS-CEN plasmids are fairly stable but $2 \mu$-plasmids can be easily lost (typically $5-10 \%$ per generation) during cell division due to unequal daughter cell repartition. Their average copy numbers exhibit a large distribution making population of transformed cells heterogeneous. The two plasmid types contained a native TRP1 gene as positive selection marker complementing a genomic trp1 mutation. The transcriptional efficiency of the tet-off synthetic promoter driving PRKp expression was controlled by the Dox concentration in a pseudo-log manner due to the presence of multiple enhancer repeats. Dose-response adjustments were performed to select Dox concentrations leading to clear and reproducible differences of growth rates (high, medium, slow) for the strain transformed by the multi-copy plasmid. The same concentrations were subsequently used for experiments involving the ARS-CEN plasmid.

Particular attention was drawn to define controlled and reproducible culture conditions. For a given level of PRKp expression, toxicity (as judged by cell growth rate), can depend on initial cell metabolic status. It was thus critical to define reproducible culture conditions and to secure the initial absence of PRKp expression. Growth of frozen cell stock on petri dishes to obtain isolated clones followed by clone pooling, was found to be an optimal starting material. The next step was to define three Dox concentrations causing undetectable, medium, and strong counter-selection during the subsequent liquid culture. For experiments, a controlled shift (lowering) of Dox concentration was required to induce PRKp expression following the initial liquid pre-culture at high Dox $(2 \mu \mathrm{g} / \mathrm{ml})$ concentration. Conditions minimalizing cell stress associated during this step with external factors like centrifugation, temperature or culture media changes were determined using reproducibility of growth rates and plasmid copy number evolution as criteria. Time series determinations of plasmid copy number and PRKp activities were performed by sampling bulk cultures following Dox concentration changes as illustrated in Fig.1. To evaluate the growth phenotypes of individual cells, culture samples were diluted with fresh culture media to generate water-in-oil emulsion of droplets. The dilution was adjusted so that the majority of droplets were empty or contained a single cell.

\subsection{Bulk cell growths as a function of plasmid type and induction.} 1605-PRK-CEN and 1605-PRK-2 $\mu$ strains were cultivated at the three Dox concentrations previously determined leading to repressed, intermediate and fully induced PRKp expressions (Fig. 2). In the case of the 1605-PRK-CEN strain, similar growth curves were observed for the repressed (Dox=2 $\mu \mathrm{g} / \mathrm{ml}$ ) and intermediate (Dox $=0.2 \mu \mathrm{g} / \mathrm{ml}$ ) expression states (Fig. 2A). In contrast, cells 1605-PRK-2 $\mu$ exhibited three clearly distinct growth behaviors depending on Dox concentrations (Fig2.B). In the conditions of full induction, growth rate was significantly faster for cells transformed by the PPRK-CEN plasmid in comparison to the $2 \mu$-plasmid case. However, a delay of about 7 hours of culture, (3-4 cell doubling) was needed to establish this difference. This delay could correspond to the duration required for PRK gene induction and corresponding protein accumulation.

The above observations established that for a low copy number plasmid, intermediate Dox level does not allow PRKp to reach expression levels that affect cell growth. Such a situation was in contrast to the full induction of the pPRK-CEN plasmid or for full and intermediate induction levels of the multi-copy 
plasmid. In the latter case, growth inhibition was stronger with the multi-copy plasmid. This experiment demonstrated that the experimental model allowed us to define at least four types of PRKp expression/ growth phenotype relationships (none, intermediate, strong and maximal effects). Consequently, for similar expression cassettes and induction levels, observed effects were much more marked with $2 \mu$ plasmids. Careful examination of growth curves evidenced that for the intermediate induction level and the $2 \mu$-plasmid, inhibition of growth decreases with time. After $15 \mathrm{~h}$ of partial induction, the growth rate for the 1605-PRK-2 $\mu$ cells reached similar value to the one observed in the fully repressed condition. This suggested that cells transformed with the $2 \mu$-plasmid might be able to adjust the level of toxicity by reducing copy number to reach a situation similar to the one observed with the ARS-CEN-based plasmid. At this point, it is important to note that a threshold of PRKp expression level was required to affect cell growth and that plasmid copy number adjustment might in some way compensate for initial difference of PRK expression. These findings will be further confirmed by direct analysis of plasmid copy number and PRKp activity changes during time courses.

\subsection{Plasmid copy number and PRK activity relationships with cell growth phenotypes}

Time courses of plasmid copy numbers and PRKp activities were monitored during the same cultures as the growth curves previously described (Fig.3). Plasmid copy number quantifications were normalized using the single chromosomal copy of the ALG9 gene in order to correct for DNA recovery yields (Fig.3 A\&B). Concerning the 1605-PRK-CEN strain, plasmid copy number remained in the 0.8 to 1.6 copy/cell range independently of PRKp expression levels and culture durations. This confirmed that the ARS-CEN copy number remained under the control of mechanisms similarly regulating chromosomal DNA replication. Cells transformed with the $2 \mu$-plasmid exhibited a higher copy number (12-14 copies per cell) in the Dox repressed state. This level remained constant within a margin of error during the pre-culture and the subsequent $20 \mathrm{~h}$ of culture at $2 \mu \mathrm{g} / \mathrm{ml}$ Dox. Such a high copy number is standard for plasmids involving the $2 \mu$-origin in the absence of strong positive or negative selection (Jordan et al., 1996). Dox concentration shifts (from 2 to $0.2 \mu \mathrm{g} / \mathrm{ml}$ or absence) induced partial or full enzyme expression and caused a clear and progressive decrease (more than 2 fold in 15h) of plasmid copy number with a similar time dependence and that extended to the two conditions. However, the final copy number ( 5-6 copies/cell) remained significantly higher than the one observed for ARS-CEN plasmids. Observation of similar copy number values for the partial and full induction contrasted with the differential impact previously illustrated on growth curves. However, this finding has to be mitigated considering that expressed PRK activities and metabolic disturbance might only partially reflect gene copy numbers (see latter).

To be able to better interpret results, PRKp activities were quantified into cell extracts obtained from the same experiments (Fig.3 C \& D). While copy numbers for ARS-CEN-constructs were identical regardless of Dox concentrations and induction durations, associated PRKp activities markedly differed. Activities appeared fairly independent of culture duration for the full and partial induction conditions but exhibited some increase at the shorter times for the lower PRK expression level. These results also show that in the fully repressed state, some residual PRKp expression was still present while being 100 -fold lower than ones observed at maximal induction. From the ensemble of these results and the growth observations, the threshold for PRKp activities able to impact cell growth was evaluated to be $\sim 10 \mathrm{nmoles} / \mathrm{min} / \mathrm{mg}$ of total proteins. PRKp activity levels for the $2 \mu$-construct followed similar time courses in experiments involving partial and full induction, consistent with similar copy number evolutions. However, for technical reasons (low cell density) the initial time course of PRKp activities cannot be accurately determined during the first 12 hours of incubation (arbitrary dotted on the figure) following DOX concentration shifts. During this initial period, a simple relationship between copy number and expressed activity is not expected. This transient phase results from time required for transcriptional de-repression and protein accumulation in the growing population. Final protein level is 
rarely expected to be proportional to transcription and copy numbers (McManus et al., 2015) (Barrett et al., 2012) (Wethmar et al., 2010) (Tang and Amon, 2013).

270 PRKp activities reached similar levels for partial or full induction of the $2 \mu$-construct and induction times ranging from 12 to 20h, when effects on cell growth rates markedly differed (Fig. 2 and 3). This lack of correlation was not observed for the ARS-CEN construct that featured stable copy number during PRKp induction course. It is thus tempting to associate these contrasting behaviors to some adaptation associated with plasmid properties. Growth curves (Fig. 2) upon full induction of PRKp expression can be accurately simulated by a model (data not shown) involving a mix of two subpopulations, one corresponding to dying cells expressing PRKp above a lethal threshold and the other corresponding to still efficiently growing cells expressing lower PRKp levels. Depending on parameters (dying rate and cell division time) and proportions of the two subpopulations, growth arrest after few generations or only reduced apparent growth rates are predicted. Development of such heterogeneity within an initially clonal population might appear surprising. In fact, it could be easily explained by the initial distribution of copy number for the $2 \mu$-constructs that is absent with ARS-CEN plasmids. In such conditions, PRKp expression in cells initially featuring high plasmid copy number will rapidly be lethal. In contrast, a nonlethal effect is expected for cells initially featuring a lower copy number, preserving potentiality for cell division and allowing further lowering of copy number through unequal plasmid repartition. Such mechanism is not expected with ARS-CEN construct and appeared globally fully consistent with observations.

\subsection{Micro-compartment based analysis of toxicity adaptation mechanisms}

At this point, and while reconciliation of growth phenotypes, copy number evolution and PRKp expression could appeared generally good enough, potential impact of the copy number heterogeneity associated with the $2 \mu$-construct has to be confirmed. Assuming a population of cells in the bulk culture containing heterogeneous copy numbers of the $2 \mu$-construct, different phenotypes must be evidenced by isolating and monitoring growth of individual cells into micro-compartments. A microfluidic device, provided by the LCMD (Fig.S1), consisting of a water in oil emulsion forming unit and an observation chamber was used for such purpose following micro-compartmentation of induced or repressed bulk cultures. Samples withdrawn after 10h liquid culture at different Dox concentration were diluted (same culture media and Dox concentrations) in order to generate droplets containing mostly no cell or single cells. The droplets were observed after $24 \mathrm{~h}$ of additional incubation at $30^{\circ} \mathrm{C}$ and the number of cells per droplet were counted to evaluate growth potentiality. Counts were roughly classified into three groups: no growth (dead cells), 4-10 cells and more than 10 cells/droplet (Fig. 4A).

Control experiments with cells transformed with plasmids lacking the PRKp expression cassette led to droplets containing only fast growing cells indicating that encapsulation did not induce growth heterogeneity in the absence of PRK expression. Similarly, for cells with the fully repressed PRKp expression, a large majority (70\% for the $2 \mu$-based and $83 \%$ for ARS-CEN-based constructs) of droplets contained more than 10 cells following incubation (Fig. 4A and B, Table S2). In contrast, a near absence of growth (1 to 3 cells per droplet) or some limited growth (4 to 10 cells per droplet) was observed for the majority of droplets containing cells encapsulated from a fully induced (no DOX) bulk culture. Partial induction of $2 \mu$-construct containing cells in bulk culture resulted after microcompartmentation in a more balanced distribution of the three types of growth. In the same conditions (repressed and partial induction), the fast-growing subpopulation was always predominant with ARSCEN-constructs. The small proportion of droplets containing non-growing cells observed in the repressed state both with the $2 \mu$ - and the ARS-CEN constructs, likely resulted from a low proportion of plasmid-free cells having accumulated during the bulk culture. This was confirmed by the observation of a $98 \%$ survival rate for repressed cells transformed by the $2 \mu$-construct when further cultivated on a medium supplemented with tryptophan. 
This work suggested that growth inhibition phenotypes observed upon controlled PRKp expression mostly resulted from population heterogeneity preexisting in bulk cultures. Comparison of growth behaviors in bulk (Fig 2) and in droplets (Fig 4B) illustrated that the micro-fluidic approach was more prone to detect moderate toxicity of gene expression than analysis of growth rates in bulk cultures. For the multicopy plasmid construction, a large majority $(63+/-6 \%)$ of droplets featuring no growing cells were counted in the absence of Dox, when $70+/-7 \%$ of droplets accumulated more than 10 cells in the fully repressed condition (Dox $=2 \mu \mathrm{g} / \mathrm{ml}$ ). Approximatively the same proportions of droplets containing no growing, 4-10 cells/droplet or more than 10 cells/droplet were observed with the $2 \mu$-constructs and an intermediate $(0.2 \mu \mathrm{g} / \mathrm{ml})$ Dox concentration. These results are in accordance with the growth curves shown in Fig 2 and Table 1 and illustrated three clearly distinct growth behaviors depending on Dox concentrations. Concerning the ARS-CEN-construct, $83+/-13 \%$ and $61+/-16 \%$ of droplets contained more than 10 cells were counted for the fully repressed and intermediate Dox conditions respectively. In contrast, only $19+/-8 \%$ of droplets contained 10 cells or more were observed for fully induced condition (no Dox). These results are consistent with the similarity of growth curves in the repressed and intermediate expression states. Thus differential growth in droplets encapsulating cells from a bulk liquid culture likely resulted mostly from the preexisting copy number heterogeneity in the population with an additional contribution of cells having lost their plasmid during the bulk culture.

\section{Conclusions}

PRKp activity is toxic by interfering with critical metabolic branches involved in amino-acid and nucleotide biosynthesis. This resulted in a clear-cut threshold value for toxicity of PRKp expression that plays the role of amplifier for the functional impact of the natural scattering of $2 \mu$-construct copy number. Our model allowed us to address how yeast cells transformed with plasmids involving ARSCEN- and $2 \mu$-origin and carrying a conditional PRKp expression cassette responded to the conditional protein expression through adjustment of plasmid copy number, gene expression, and finally cell growth rates. The PRKp expression model is of particular interest in constituting a key step for the reconstruction of synthetic microorganisms able to capture (or recapture) carbon dioxide through an artificial Calvin cycle. However, the model has a more general interest for tuning strategies of engineering involving sequence of critically balanced enzymatic steps prone to accumulate toxic intermediates. Control of plasmid copy number is potentially a powerful approach for engineering optimization. Natural unequal plasmid partition over cell divisions progressively create a distribution of copy numbers counteracted by a large range of regulation mechanisms acting at level of plasmid replication. However, these mechanisms can be disrupted in a dynamic manner by strong positive or negative selection pressures associated with plasmid encoded functional cassettes. Playing with such mechanisms is of interest to optimize the production of biomolecule and cause a significant metabolic load. Maintaining multi-copy plasmid in the off-state during the growth phase before activation, once high cell density is reached and cell division arrested, is a classical approach to optimize expression. However, our work illustrated that copy number distribution can led to the formation of subpopulations with markedly distinct phenotypes.

\section{Acknowledgements}

This work was supported by Grant ANR-14-CE08-0008-02 from Agence Nationale de la Recherche, France.

We thank Roxanne Diaz (English natives speaker) for language improvement of the manuscript. 
Figure 1. Experiment flow chart. Plate incubation was performed in solid YNB-trp supplemented with 2 $\mu \mathrm{g} / \mathrm{ml}$ Dox at $30^{\circ} \mathrm{C}$. Washes were performed with YNB-trp without Dox and culture started at $\mathrm{OD}_{600}=0.01$. Liquid cultures were performed in the same media containing various Dox concentrations at $30^{\circ} \mathrm{C}$ with $200 \mathrm{rpm}$ shaking. Samples were either pelleted for qPCR and HPLC-MS analysis at 0,7 , $9,11,13,15,17,19$ and $21 \mathrm{~h}$ of culture or diluted to $\mathrm{OD}_{600}=0.015$ after $10 \mathrm{~h}$ culture for encapsulation.

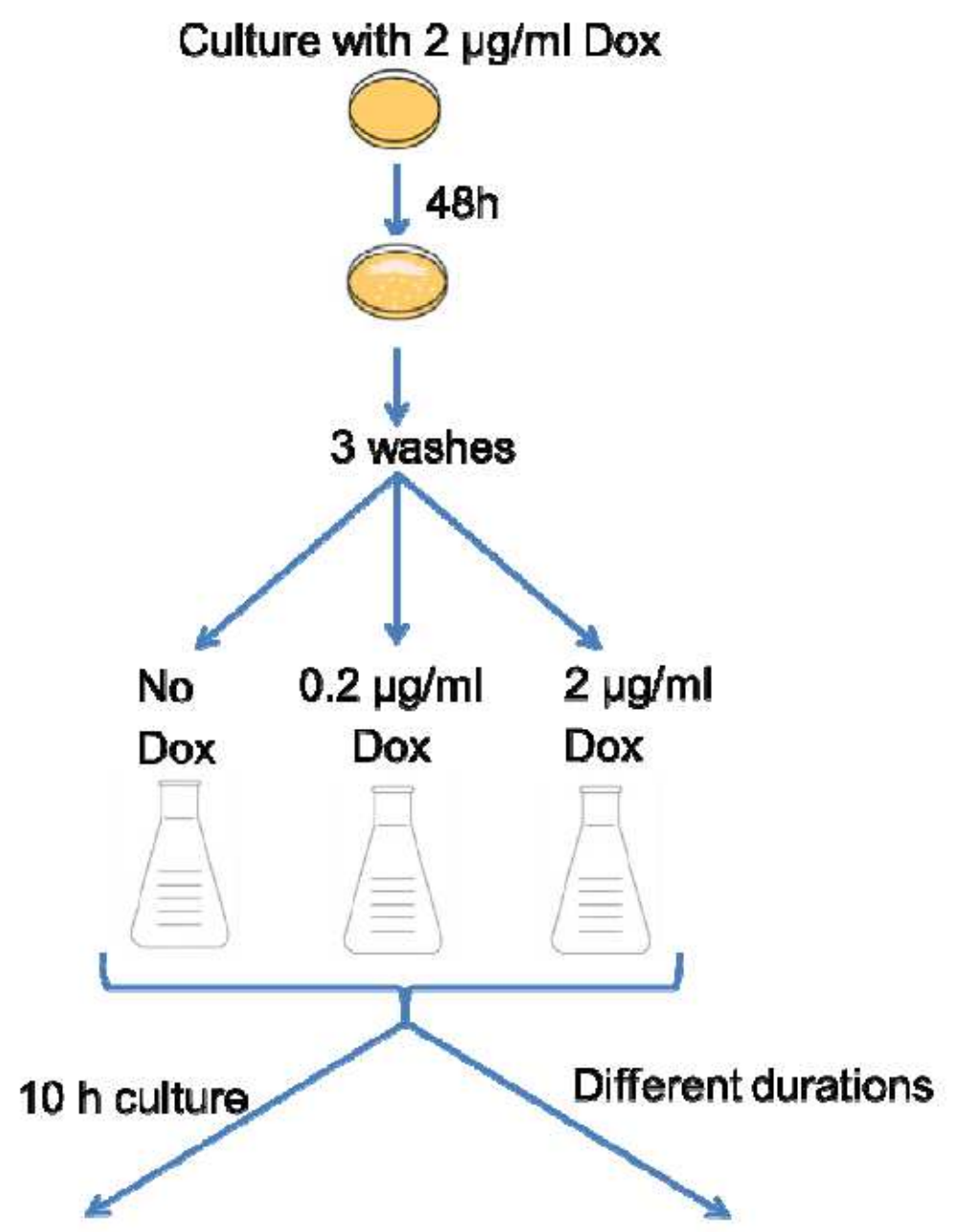

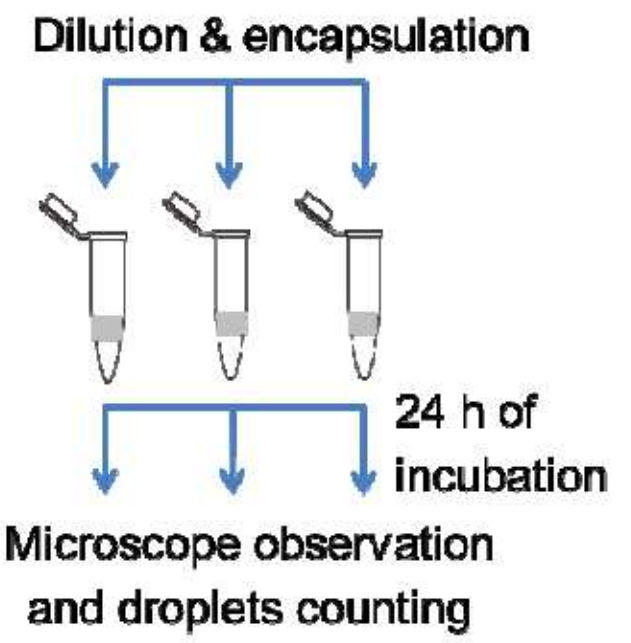


Figure 2. Growth curves of yeast cells at different Dox concentrations $(\rightarrow 0 \mu \mathrm{g} / \mathrm{ml},-0.2 \mu \mathrm{g} / \mathrm{ml}$, $-2 \mu \mathrm{g} / \mathrm{ml}$ ) for cells bearing centromeric (A) or multi-copy plasmids (B).

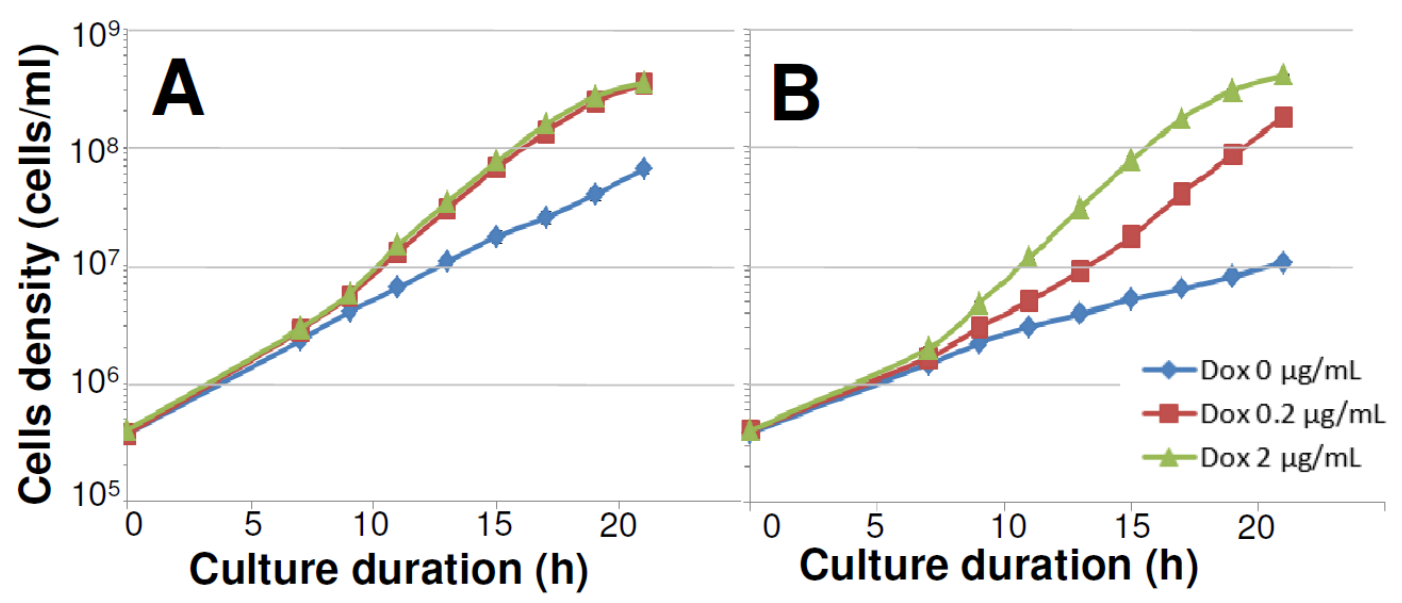

Figure 3. Time dependence of relative plasmid copy number as function of Dox concentration in culture media $(\neg 0 \mu \mathrm{g} / \mathrm{ml},-0.2 \mu \mathrm{g} / \mathrm{ml}, \leftarrow 2 \mu \mathrm{g} / \mathrm{ml}$ ) for centromeric (A) or multi-copy (B) plasmids. Time dependence of PRKp activity for cells with centromeric $(C)$ or multi-copy $(D)$ plasmids. Dotted lines are

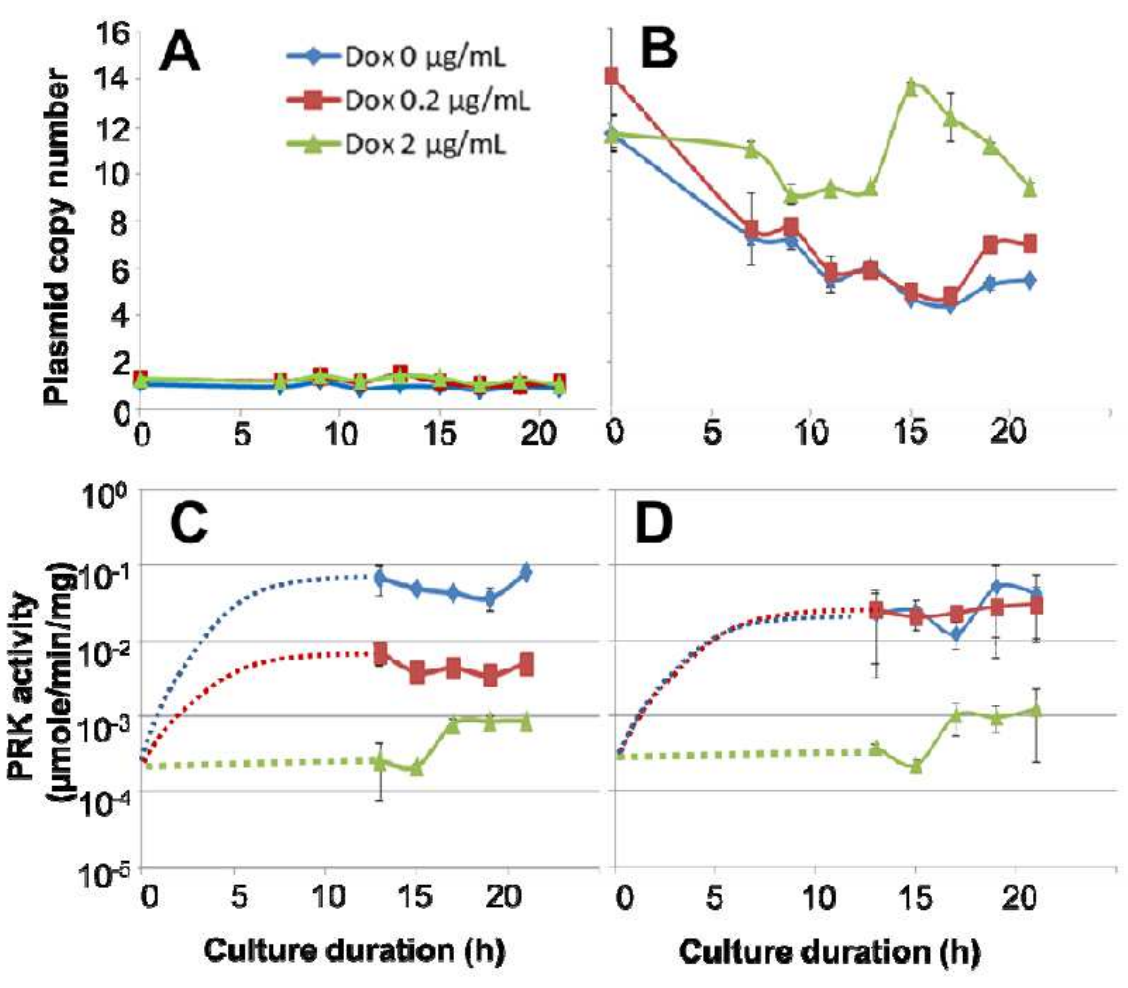


Figure 4. (4A) Microscopy observation of droplets for different Dox concentrations and plasmid types. High (full circles), medium (dashed circles) and low (dotted circles) cell densities in droplets. (4B) Cell growth analysis in droplets after $24 \mathrm{~h}$ incubation. Classified by (A) Dox concentrations or (B-D) growth level in the droplet. 1 to 3 cells per droplet (black boxes), 4 to 10 cells per droplet (grey boxes), and more than 10 cells per droplet (white boxes). A control was realized with cells transformed with multicopy plasmid lacking the PRKp expression cassette, in presence of $2 \mu \mathrm{g} / \mathrm{ml}$ of Doxycycline and tryptophan supplementation $(2+$ trp). Color codes are identical for upper and lower panels. Values are averages of microfluidic experiments triplicates.
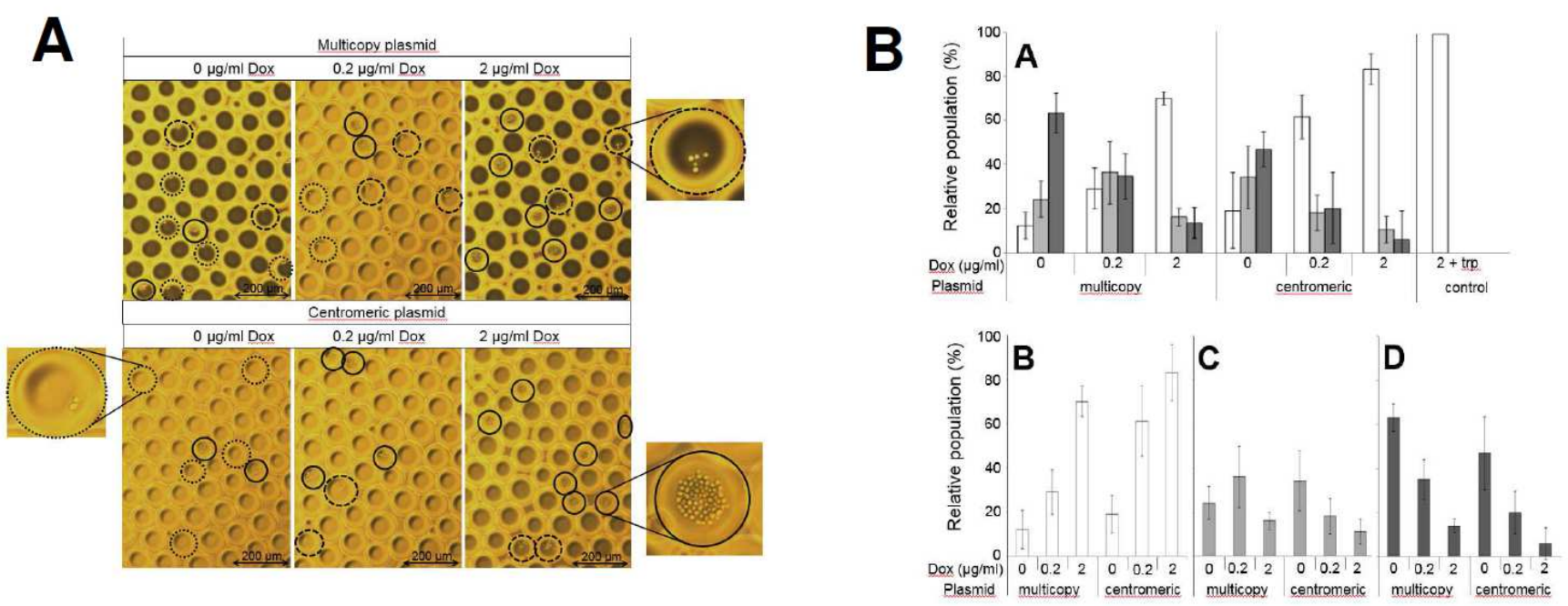

Table 1. Results summary. Growth rate $(\mu)$ calculated between 13 and $15 \mathrm{~h}$ of culture. Relative plasmid copy numbers measured at start of culture (Oh) and after $21 \mathrm{~h}$ and fold changes. PRKp activities after $21 \mathrm{~h}$ of incubation. Microfluidic observations in droplets of the relative populations of fast and slow growing cells.

\begin{tabular}{|c|c|c|c|c|c|c|c|}
\hline \multirow[b]{2}{*}{$\begin{array}{c}\text { Plasmid } \\
\text { type }\end{array}$} & \multirow[b]{2}{*}{$\begin{array}{c}\text { Dox } \\
(\mu \mathrm{g} / \mathrm{ml})\end{array}$} & \multirow{2}{*}{$\begin{array}{c}\text { Growth rate } \\
(\mu) \\
13-15 h \\
\left(h^{-1}\right)\end{array}$} & \multicolumn{2}{|c|}{ Relative copy numbers } & \multirow{2}{*}{$\begin{array}{c}\text { PRK activity } \\
21 \mathrm{~h} \\
\left(\begin{array}{c}\mu \mathrm{moles} / \mathrm{min} / \\
\mathrm{mg})\end{array}\right.\end{array}$} & \multicolumn{2}{|c|}{ Microfluidic } \\
\hline & & & $\begin{array}{l}\text { Value } \\
\text { Oh - } 21 \mathrm{~h}\end{array}$ & $\begin{array}{c}\text { Fold } \\
\text { change } \\
\text { T21/T0 }\end{array}$ & & $\begin{array}{l}\text { \% cells } \\
\text { Slow } \\
\text { growing }\end{array}$ & $\begin{array}{c}\% \text { cells } \\
\text { Fast } \\
\text { growing }\end{array}$ \\
\hline \multirow{3}{*}{ multicopy } & 0 & 0.06 & $12 \pm 0.7-5 \pm 0.0$ & 0,42 & $4.10^{-2} \pm 3.10^{-2}$ & $63 \pm 8$ & $12 \pm 9$ \\
\hline & 0.2 & 0.14 & $14 \pm 3.0-7 \pm 0.1$ & 0.50 & $3.10^{-2} \pm 2.10^{-2}$ & $35 \pm 14$ & $29 \pm 10$ \\
\hline & 2 & 0.20 & $12 \pm 0.8-9 \pm 0.2$ & 0.75 & $1.10^{-3} \pm 1.10^{-3}$ & $14 \pm 4$ & $70 \pm 7$ \\
\hline \multirow{3}{*}{ centromeric } & 0 & 0.11 & $1.1 \pm 0.2-0.7 \pm 0.2$ & 0.64 & $8.10^{-2} \pm 4.10^{-3}$ & $47 \pm 14$ & $19 \pm 8$ \\
\hline & 0.2 & 0.18 & $1.3 \pm 0.1-1.0 \pm 0.1$ & 0.77 & $5.10^{-3} \pm 1.10^{-4}$ & $20 \pm 8$ & $61 \pm 16$ \\
\hline & 2 & 0.17 & $1.3 \pm 0.1-1.1 \pm 0.1$ & 0.85 & $9.10^{-4} \pm 2.10^{-4}$ & $6 \pm 6$ & $83 \pm 13$ \\
\hline
\end{tabular}


Figure S1. Microfluidic system for cell encapsulation in droplets and observation of growth. (A) Flowfocusing geometry: cells in culture media (vertical arrow), Oil and surfactant (arrows). (B) Multi-line
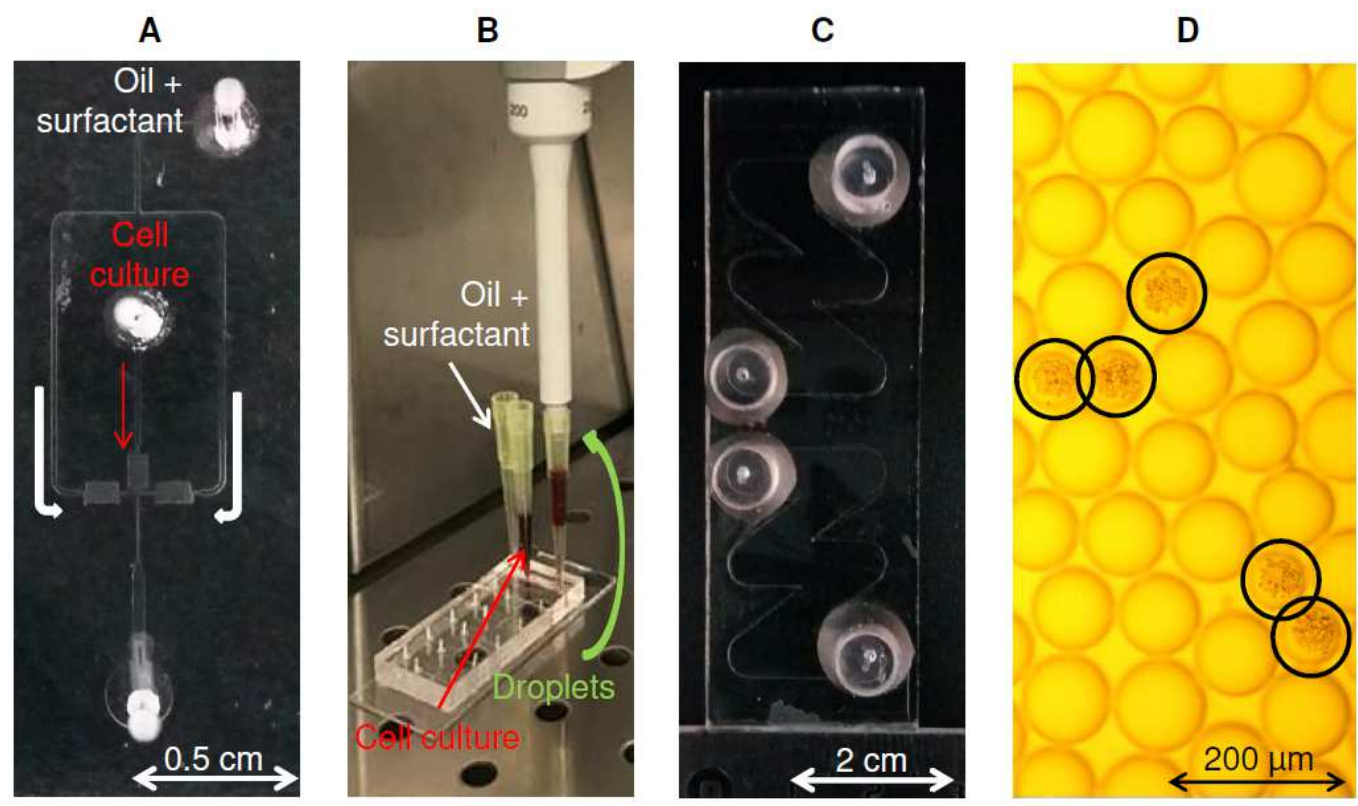

Table S1. QPCR primer list.

\begin{tabular}{lll}
\hline Gene & \multicolumn{2}{c}{$\mathbf{5}^{\prime} \mathbf{-} \mathbf{3}^{\prime}$ sequence } \\
\hline \multirow{2}{*}{ ALG9 } & Forward & CACGGATAGTGGCTTTGGTGAACAATTAC \\
& Reverse & TATGATTATCTGGCAGCAGGAAAGAACTTGGG \\
\multirow{2}{*}{ PRK6 } & Forward & ACACGCAAACACAAATAC \\
& Reverse & TACCACAACCAGAATCAC \\
\hline
\end{tabular}


406 Table S2. Relative numbers of droplets featuring low, medium and high number of cells following 407 incubation of initially single cell transformed with centromeric and multi-copy plasmids in medium 408 containing various Dox levels.

\begin{tabular}{|c|c|c|c|c|}
\hline Plasmide type & $\operatorname{Dox}(\mu \mathrm{g} / \mathrm{ml})$ & 1-3 cells/droplet & 4-10 cells/droplet & $>10$ cells/droplet \\
\hline \multirow{3}{*}{ multicopy } & 0 & $63 \% \pm 6 \%$ & $24 \% \pm$ & $12 \% \pm 9 \%$ \\
\hline & 0.2 & $35 \% \pm 9 \%$ & $36 \% \pm 14 \%$ & $29 \% \pm 10 \%$ \\
\hline & 2 & $14 \% \pm 3 \%$ & $16 \% \pm$ & $70 \% \pm 7 \%$ \\
\hline \multirow{3}{*}{ centromeric } & 0 & $47 \% \pm 17 \%$ & $34 \% \pm 14 \%$ & $19 \% \pm 8 \%$ \\
\hline & 0.2 & $20 \% \pm 10 \%$ & $18 \% \pm$ & $61 \% \pm 16 \%$ \\
\hline & 2 & $6 \% \pm 7 \%$ & $11 \% \pm$ & $83 \% \pm 13 \%$ \\
\hline
\end{tabular}




\section{References}

Avery, S.V., 2006. Microbial cell individuality and the underlying sources of heterogeneity. Nat Rev Micro 4, 577-587. https://doi.org/10.1038/nrmicro1460

Bailey, J.E., 1993. Host-vector interactions in Escherichia coli, in: Bioprocess Design and Control. Springer Berlin Heidelberg, Berlin, Heidelberg, pp. 29-52. https://doi.org/10.1007/BFb0007195

Barrett, L.W., Fletcher, S., Wilton, S.D., 2012. Regulation of eukaryotic gene expression by the untranslated gene regions and other non-coding elements. Cell. Mol. Life Sci. 69, 3613-3634. https://doi.org/10.1007/s00018-012-0990-9

Bódi, Z., Farkas, Z., Nevozhay, D., Kalapis, D., Lázár, V., Csörgő, B., Nyerges, Á., Szamecz, B., Fekete, G., Papp, B., Araújo, H., Oliveira, J.L., Moura, G., Santos, M.A.S., Székely Jr, T., Balázsi, G., Pál, C., 2017. Phenotypic heterogeneity promotes adaptive evolution. PLOS Biol. 15, e2000644. https://doi.org/10.1371/journal.pbio.2000644

Boitard, L., Cottinet, D., Kleinschmitt, C., Bremond, N., Baudry, J., Yvert, G., Bibette, J., 2012. Monitoring single-cell bioenergetics via the coarsening of emulsion droplets. Proc. Natl. Acad. Sci. U. S. A. 109, 7181-7186. https://doi.org/10.1073/pnas.1200894109

Borodina, I., Nielsen, J., 2014. Advances in metabolic engineering of yeast Saccharomyces cerevisiae for production of chemicals. Biotechnol. J. 9, 609-620. https://doi.org/10.1002/biot.201300445

Çakar, Z.P., Sauer, U., Bailey, J.E., 1999. Metabolic engineering of yeast: the perils of auxotrophic hosts. Biotechnol. Lett. 21, 611-616. https://doi.org/10.1023/A:1005576004215

Chen, X., Zhou, L., Tian, K., Kumar, A., Singh, S., Prior, B.A., Wang, Z., 2013. Metabolic engineering of Escherichia coli: A sustainable industrial platform for bio-based chemical production. Biotechnol. Adv. 31, 1200-1223. https://doi.org/10.1016/j.biotechadv.2013.02.009

Clarke, L., Carbon, J., 1980. Isolation of a yeast centromere and construction of functional small circular chromosomes. Nature 287, 504-509. https://doi.org/10.1038/287504a0

Da Silva, N.A., Srikrishnan, S., 2012. Introduction and expression of genes for metabolic engineering applications in Saccharomyces cerevisiae. FEMS Yeast Res. 12, 197-214. https://doi.org/10.1111/j.1567-1364.2011.00769.x

Damodaran, S.P., Eberhard, S., Boitard, L., Rodriguez, J.G., Wang, Y., Bremond, N., Baudry, J., Bibette, J., Wollman, F.-A., 2015. A Millifluidic Study of Cell-to-Cell Heterogeneity in GrowthRate and Cell-Division Capability in Populations of Isogenic Cells of Chlamydomonas reinhardtii. PLoS ONE 10, e0118987. https://doi.org/10.1371/journal.pone.0118987

Dingermann, T., Frank-Stoll, U., Werner, H., Wissmann, A., Hillen, W., Jacquet, M., Marschalek, R., 1992. RNA polymerase III catalysed transcription can be regulated in Saccharomyces cerevisiae by the bacterial tetracycline repressor-operator system. EMBO J. 11, 1487-1492.

Futcher, A.B., Cox, B.S., 1984. Copy number and the stability of 2-micron circle-based artificial plasmids of Saccharomyces cerevisiae. J. Bacteriol. 157, 283-290.

Futcher, A.B., Cox, B.S., 1983. Maintenance of the 2 microns circle plasmid in populations of Saccharomyces cerevisiae. J. Bacteriol. 154, 612-622.

Gerbaud, C., Guérineau, M., 1980. $2 \mu \mathrm{m}$ plasmid copy number in different yeast strains and repartition of endogenous and $2 \mu \mathrm{m}$ chimeric plasmids in transformed strains. Curr. Genet. 1, 219-228. https://doi.org/10.1007/BF00390947

Gnügge, R., Liphardt, T., Rudolf, F., 2016. A shuttle vector series for precise genetic engineering of Saccharomyces cerevisiae. Yeast 33, 83-98. https://doi.org/10.1002/yea.3144

Gnügge, R., Rudolf, F., 2017. Saccharomyces cerevisiae Shuttle vectors. Yeast 34, 205-221. https://doi.org/10.1002/yea.3228

Görgens, J.F., van Zyl, W.H., Knoetze, J.H., Hahn-Hägerdal, B., 2001. The metabolic burden of the PGK1 and ADH2 promoter systems for heterologous xylanase production by Saccharomyces cerevisiae in defined medium. Biotechnol. Bioeng. 73, 238-245. https://doi.org/10.1002/bit.1056

Grünberger, A., Schöler, K., Probst, C., Kornfeld, G., Hardiman, T., Wiechert, W., Kohlheyer, D., Noack, S., 2017. Real-time monitoring of fungal growth and morphogenesis at single-cell resolution. Eng. Life Sci. 17, 86-92. https://doi.org/10.1002/elsc.201600083

Grünberger, A., Wiechert, W., Kohlheyer, D., 2014. Single-cell microfluidics: opportunity for bioprocess development. Cell Pathw. Eng. 29, 15-23. https://doi.org/10.1016/j.copbio.2014.02.008 
Guyot, S., Gervais, P., Young, M., Winckler, P., Dumont, J., Davey, H.M., 2015. Surviving the heat: heterogeneity of response in Saccharomyces cerevisiae provides insight into thermal damage to the membrane. Environ. Microbiol. 17, 2982-2992. https://doi.org/10.1111/1462-2920.12866

Harrison, E., Koufopanou, V., Burt, A., MacLean, R.C., 2012. The cost of copy number in a selfish genetic element: the 2- $\mu \mathrm{m}$ plasmid of Saccharomyces cerevisiae. J. Evol. Biol. 25, 2348-2356. https://doi.org/10.1111/j.1420-9101.2012.02610.x

Holland, S.L., Reader, T., Dyer, P.S., Avery, S.V., 2014. Phenotypic heterogeneity is a selected trait in natural yeast populations subject to environmental stress. Environ. Microbiol. 16, 1729-1740. https://doi.org/10.1111/1462-2920.12243

Jahn, M., Günther, S., Müller, S., 2015. Non-random distribution of macromolecules as driving forces for phenotypic variation. Environ. Microbiol. • Extrem. 25, 49-55. https://doi.org/10.1016/j.mib.2015.04.005

Jahn, M., Vorpahl, C., Türkowsky, D., Lindmeyer, M., Bühler, B., Harms, H., Müller, S., 2014. Accurate Determination of Plasmid Copy Number of Flow-Sorted Cells using Droplet Digital PCR. Anal. Chem. 86, 5969-5976. https://doi.org/10.1021/ac501118v

Jordan, B., E., Mount, Robert C, Hadfield, Christopher, 1996. Determination of plasmid copy number in yeast 193-203.

Karim, A.S., Curran, K.A., Alper, H.S., 2013. Characterization of plasmid burden and copy number in Saccharomyces cerevisiae for optimization of metabolic engineering applications. FEMS Yeast Res. 13, 10.1111/1567-1364.12016. https://doi.org/10.1111/1567-1364.12016

Kazemi Seresht, A., Nørgaard, P., Palmqvist, E.A., Andersen, A.S., Olsson, L., 2013. Modulating heterologous protein production in yeast: the applicability of truncated auxotrophic markers. Appl. Microbiol. Biotechnol. 97, 3939-3948. https://doi.org/10.1007/s00253-012-4263-1

Khatun, M.M., Yu, X., Kondo, A., Bai, F., Zhao, X., n.d. Improved ethanol production at high temperature by consolidated bioprocessing using Saccharomyces cerevisiae strain engineered with artificial zinc finger protein. Bioresour. Technol. https://doi.org/10.1016/j.biortech.2017.05.088

Kim, S.R., Skerker, J.M., Kong, I.I., Kim, H., Maurer, M.J., Zhang, G.-C., Peng, D., Wei, N., Arkin, A.P., Jin, Y.-S., 2017. Metabolic engineering of a haploid strain derived from a triploid industrial yeast for producing cellulosic ethanol. Metab. Eng. 40, 176-185. https://doi.org/10.1016/j.ymben.2017.02.006

Krivoruchko, A., Siewers, V., Nielsen, J., 2011. Opportunities for yeast metabolic engineering: Lessons from synthetic biology. Biotechnol. J. 6, 262-276. https://doi.org/10.1002/biot.201000308

Kwak, S., Jin, Y.-S., 2017. Production of fuels and chemicals from xylose by engineered Saccharomyces cerevisiae: a review and perspective. Microb. Cell Factories 16, 82. https://doi.org/10.1186/s12934-017-0694-9

McManus, J., Cheng, Z., Vogel, C., 2015. Next-generation analysis of gene expression regulation comparing the roles of synthesis and degradation. Mol. Biosyst. 11, 2680-2689. https://doi.org/10.1039/c5mb00310e

Moriya, H., Shimizu-Yoshida, Y., Kitano, H., 2006. In Vivo Robustness Analysis of Cell Division Cycle Genes in Saccharomyces cerevisiae. PLOS Genet. 2, e111. https://doi.org/10.1371/journal.pgen.0020111

Talia, S.D., Skotheim, J.M., Bean, J.M., Siggia, E.D., Cross, F.R., 2007. The effects of molecular noise and size control on variability in the budding yeast cell cycle. Nature 448, 947-951. https://doi.org/10.1038/nature06072

Tang, Y.-C., Amon, A., 2013. Gene copy number alterations: A cost-benefit analysis. Cell 152, 394405. https://doi.org/10.1016/j.cell.2012.11.043

Teste, M.-A., Duquenne, M., François, J.M., Parrou, J.-L., 2009. Validation of reference genes for quantitative expression analysis by real-time RT-PCR in Saccharomyces cerevisiae. BMC Mol. Biol. 10, 99-99. https://doi.org/10.1186/1471-2199-10-99

Ugolini, S., Tosato, V., Bruschi, C.V., 2002. Selective Fitness of Four Episomal Shuttle-Vectors Carrying HIS3, LEU2, TRP1, and URA3 Selectable Markers in Saccharomyces cerevisiae. Plasmid 47, 94-107. https://doi.org/10.1006/plas.2001.1557

Watson, S.K., Han, Z., Su, W.W., Deshusses, M.A., Kan, E., 2016. Carbon dioxide capture using Escherichia coli expressing carbonic anhydrase in a foam bioreactor. Environ. Technol. 37, 3186-3192. https://doi.org/10.1080/09593330.2016.1181110 
Wells, E., Robinson, A.S., 2017. Cellular engineering for therapeutic protein production: product quality, host modification, and process improvement. Biotechnol. J. 12, 1600105-n/a. https://doi.org/10.1002/biot.201600105

Wethmar, K., Smink, J.J., Leutz, A., 2010. Upstream open reading frames: Molecular switches in (patho)physiology. Bioessays 32, 885-893. https://doi.org/10.1002/bies.201000037

Yen-Ting-Liu, Sau, S., Ma, C.-H., Kachroo, A.H., Rowley, P.A., Chang, K.-M., Fan, H.-F., Jayaram, M., 2014. The partitioning and copy number control systems of the selfish yeast plasmid: an optimized molecular design for stable persistence in host cells. Microbiol. Spectr. 2, 10.1128/microbiolspec.PLAS-0003-2013. https://doi.org/10.1128/microbiolspec.PLAS-00032013

530

Zhuang, Z.-Y., Li, S.-Y., 2013. Rubisco-based engineered Escherichia coli for in situ carbon dioxide recycling. Bioresour. Technol. 150, 79-88. https://doi.org/10.1016/j.biortech.2013.09.116 